(REVIEW ARTICLE)

\title{
Gastrointestinal manifestations in patients with COVID-19 infection
}

\author{
Rocha Gabriel Henrique Elisio Santos *, Campos Martins Marcus Vinicius Dantas de and Melo Bruno Vaz de
}

Surgery Department of Hospital Municipal Lourenço Jorge, Rio de Janeiro, Brazil.

Publication history: Received on 30 June 2020; revised on 08 July 2020; accepted on 09 July 2020

Article DOI: https://doi.org/10.30574/wjarr.2020.7.1.0240

\begin{abstract}
We are currently facing a major threat to public health, with a significant impact on people's lives, destabilizing societies with a high mortality rate and weakening the economy worldwide. The disease was named coronavirus disease 2019 (COVID-19). As a new infectious disease, it is extremely important to discover its clinical characteristics, especially in the initial stage, in order to help detect and isolate patients earlier and to reduce the spread of the infection. We performed a systematic literature review based on an online search in the PubMed on Jun/13/2020, 19 records were analyzed, 13954 patients were identified. This study aims to review and investigate the characteristics of gastrointestinal symptoms in patients with COVID-19, raise awareness of health professionals and facilitate early recognition as well as appropriate treatment, avoiding the spreading of the disease. In this study, we found that many of the hospitalized patients with the COVID-19 infection had at least one gastrointestinal symptom. Patients with gastrointestinal symptoms like abdominal pain, diarrhea, nausea, vomiting or anorexia deserve special attention, and it is extremely important to understand the nuances of clinical characteristics and prognosis among patients with and without these symptoms.
\end{abstract}

Keywords: COVID-19; Gastrointestinal symptoms; Abdominal pain; Diarrhea; Nausea; Vomiting; Anorexia

\section{Introduction}

We are currently facing a major threat to public health, with a significant impact on people's lives, destabilizing societies with a high mortality rate and weakening the economy worldwide. The disease was named coronavirus disease 2019 (COVID-19), by the World Health Organization (WHO) and the virus was designated SARS-CoV-2 by the International Virus Taxonomy Committee. Health systems face the challenge of demands that no one has ever seen before and there is an urgent need to characterize the range of clinical presentations of this disease, thus allowing the early identification, isolation and screening of affected patients. $[1,2,3,4,5,6,7,9,10]$

The most common symptoms at the beginning of COVID-19 are fever, cough, fatigue, myalgia, dyspnea and anosmia, while some patients also have gastrointestinal manifestations such as diarrhea, nausea, vomiting, abdominal pain and anorexia. Although symptoms may appear concomitantly, patients may also present only intestinal symptoms without the expected respiratory ones. $[1,3,4,5,6,7,11,12]$

As a new infectious disease, it is extremely important to discover its clinical characteristics, especially in the initial stage, in order to help detect and isolate patients earlier and to reduce the spread of the infection $[5,8]$

The objective of this study is to demonstrate the gastrointestinal presentations of COVID-19, drawing the attention of health professionals to their better identification, diagnosis, management and treatment.

\footnotetext{
${ }^{*}$ Corresponding author: Rocha Gabriel Henrique Elisio Santos
} 


\section{Material and methods}

We performed a systematic literature review based on an online search in the PubMed on Jun/13/2020. The following terms were used in the search engine to find matching articles: (COVID-19) AND ((abdominal pain) OR (abdominal presentation) OR (abdominal symptoms) OR (gastrointestinal symptoms) OR (gastrointestinal tract) OR (abdominal) OR (diarrhea) OR (nausea) OR (vomiting) OR (anorexia)).

Our initial search yielded 484 articles. All article titles and abstracts were read by at least one author, and selected if relevant. For the articles selected for full-text reading, at least two authors read the contents.

\section{Results}

Of the 484 articles found in our initial research, 430 articles were disregarded after reading the titles and 26 after reading the abstract. 28 articles were read by at least two authors, 09 of which were removed from the study. 19 records were elected for this review. (Figure 1).

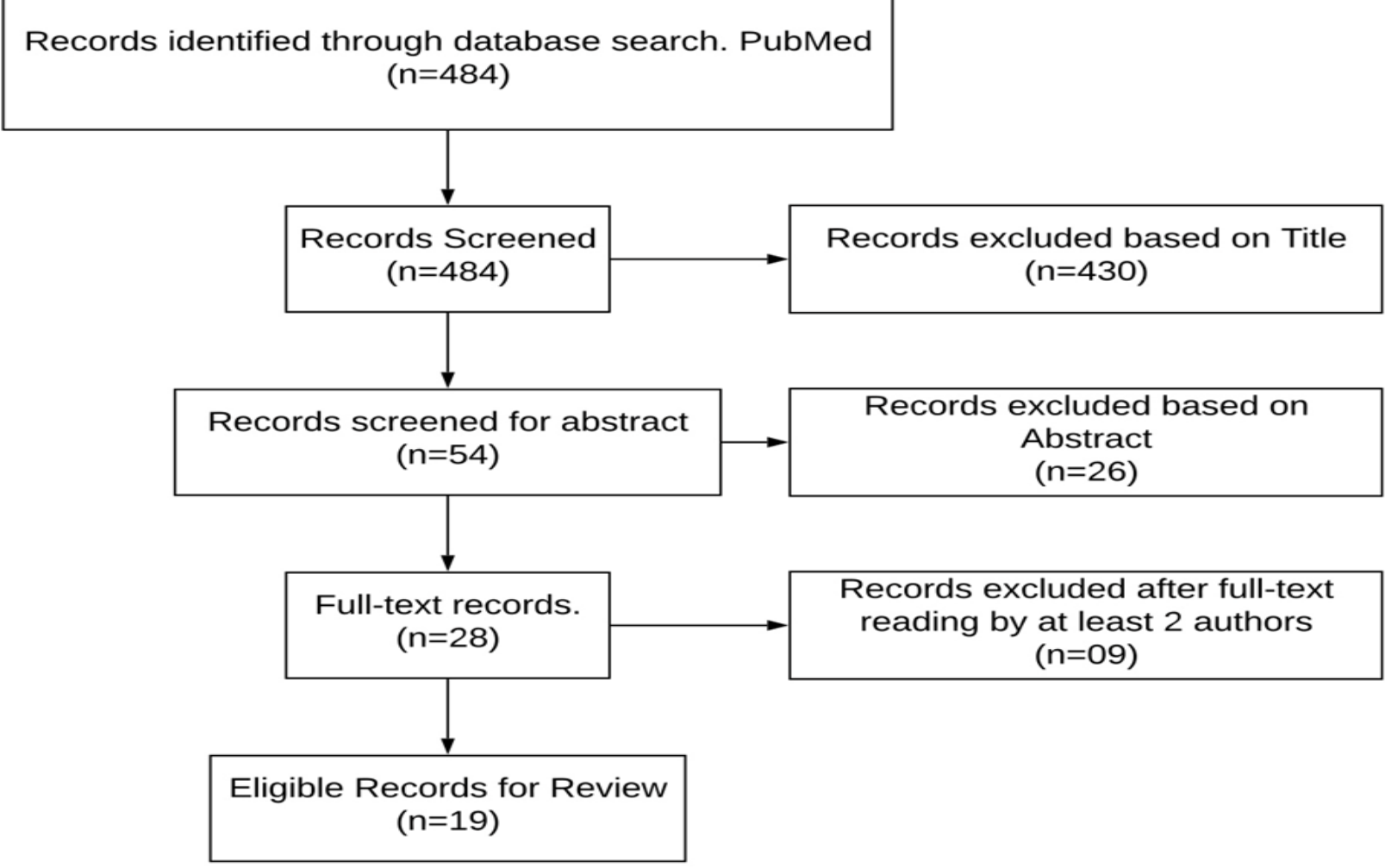

Figure 1 Selection diagram

This study aims to review and investigate the characteristics of gastrointestinal symptoms in patients with COVID-19, raise awareness of health professionals and facilitate early recognition as well as appropriate treatment, avoiding the spreading of the disease.

19 records were analyzed, 13954 patients were identified, with median ages ranging from 43.7 to 65 years, Nobel et al [4]; Reed et al [20] and Liu et al [21] did not show their age variations. Eleven records identified patients with gastrointestinal symptoms such as anorexia, diarrhea, nausea, vomiting or abdominal pain. Nine studies presented data in percentages of patients with the presence of anorexia, eight presented data from patients with nausea or vomiting, seven records grouped nausea and vomiting as a single set of symptoms. Thirteen records represented their patient with the presence of abdominal pain. Interestingly, in all records the diarrhea symptom was analyzed. (Table 1). 
Table 1 Gastrointestinal manifestations in patients with COVID-19 infection.

\begin{tabular}{|c|c|c|c|c|c|c|c|c|c|c|c|c|c|c|c|c|c|}
\hline \multirow[b]{3}{*}{ Zhang et al [13] } & \multirow{3}{*}{$\begin{array}{l}\text { Total Patients } \\
140\end{array}$} & \multirow{3}{*}{$\begin{array}{l}\text { Age } \\
57(25-87)^{*}\end{array}$} & \multicolumn{4}{|l|}{ Sex } & \multicolumn{11}{|c|}{ Symptoms } \\
\hline & & & \multicolumn{2}{|c|}{ Male } & \multicolumn{2}{|c|}{ Female } & \multicolumn{2}{|c|}{ GI Sympotoms } & \multicolumn{2}{|c|}{ Anorexia } & \multicolumn{2}{|c|}{ Diarrhea } & Nausea & \multicolumn{2}{|c|}{ Vomiting } & \multicolumn{2}{|c|}{$\begin{array}{l}\text { Abdominal } \\
\text { Pain }\end{array}$} \\
\hline & & & 71 & $50.7 \%$ & 69 & $49.3 \%$ & 55 & $39.3 \%$ & 17 & $12.1 \%$ & 18 & $12.9 \%$ & $24 \quad 17.1 \%$ & 7 & $5.0 \%$ & 8 & $5.7 \%$ \\
\hline Guang et al [14] & 1099 & $47(35-58)^{*}$ & 640 & $58.2 \%$ & 459 & $41.8 \%$ & - & & - & & 42 & $3.8 \%$ & $555 \%$ & & & - & \\
\hline Chen et al [15] & 99 & $55.5(21-81)^{\wedge}$ & 67 & $67.7 \%$ & 32 & $32.3 \%$ & - & & - & & 2 & $2.0 \%$ & $11 \%$ & & & - & \\
\hline Lin et al [7] & 95 & $45.3(+/-18.3)^{\wedge}$ & 45 & $47.7 \%$ & 50 & $52.6 \%$ & 58 & $61.1 \%$ & 17 & $17.9 \%$ & 23 & $24.2 \%$ & $17 \quad 17.9 \%$ & 4 & $4.2 \%$ & 2 & $2.1 \%$ \\
\hline Pan et al [6] & 204 & $52.91(+/-15.98)^{\wedge}$ & 107 & $52.5 \%$ & 97 & $47.5 \%$ & 103 & $50.5 \%$ & 81 & $39.7 \%$ & 35 & $17.2 \%$ & - & 4 & $2.0 \%$ & 2 & $1.0 \%$ \\
\hline Zhou et al [16] & 254 & $50(36-65)^{*}$ & 115 & $45.3 \%$ & 139 & $54.7 \%$ & 66 & $26.0 \%$ & - & & 46 & $18.1 \%$ & $218.3 \%$ & 15 & $5.9 \%$ & 3 & $1.2 \%$ \\
\hline Zhang G et al [17] & 221 & $55(39-66.5)^{*}$ & 108 & $48.9 \%$ & 113 & $51.1 \%$ & - & & 80 & $36.2 \%$ & 25 & $11.3 \%$ & - & - & & 5 & $2.3 \%$ \\
\hline Liam et al [18] & 465 & $45(5-88)^{*}$ & 243 & $52.3 \%$ & 222 & $47.7 \%$ & - & & - & & 36 & $7.7 \%$ & $224.7 \%$ & & & - & \\
\hline Nobel et al [4] & 279 & - & - & & - & & 97 & $34.8 \%$ & - & & 56 & $20.1 \%$ & $6322.6 \%$ & & & - & \\
\hline Wang et al [19] & 1012 & $50(39-58)^{*}$ & 524 & $51.8 \%$ & 488 & $48.2 \%$ & - & & - & & 152 & $15.0 \%$ & - & 36 & $3.6 \%$ & 37 & $3.7 \%$ \\
\hline Redd et al [20] & 318 & - & - & & - & & 195 & $61.3 \%$ & 110 & $34.6 \%$ & 107 & $33.6 \%$ & $84 \quad 26.4 \%$ & 49 & $15.4 \%$ & 46 & $14.5 \%$ \\
\hline Liu et al [21] & 321 & - & - & & - & & 26 & $8.1 \%$ & - & & 23 & $7.2 \%$ & $3310.3 \%$ & & & 3 & $0.9 \%$ \\
\hline Chen $Q$ et all [22] & 102 & $47.5(+/-14.6)^{\wedge}$ & 56 & $54.9 \%$ & 46 & $45.1 \%$ & - & & 36 & $35.3 \%$ & 23 & $22.5 \%$ & $14 \quad 13.7 \%$ & 6 & $5.9 \%$ & 6 & $5.9 \%$ \\
\hline Zheng et al [23] & 1320 & $50(40-57)^{*}$ & 579 & $43.9 \%$ & 741 & $56.1 \%$ & 191 & $14.5 \%$ & 62 & $4.7 \%$ & 107 & $8.1 \%$ & $574.3 \%$ & & & 11 & $0.8 \%$ \\
\hline Shang et al [24] & 307 & $46(35-55)^{*}$ & 164 & $53.4 \%$ & 143 & $46.6 \%$ & - & & 111 & $36.2 \%$ & 16 & $5.2 \%$ & $113.58 \%$ & & & - & \\
\hline Chen A et al [25] & 101 & $48.32(+/-14.34)^{\wedge}$ & 41 & $40.6 \%$ & 60 & $59.4 \%$ & 75 & $74.3 \%$ & 54 & $53.5 \%$ & 51 & $50.5 \%$ & $30 \quad 29.7 \%$ & 14 & $13.9 \%$ & 26 & $25.7 \%$ \\
\hline Díaz et al [26] & 7213 & $40^{*}$ & 3606 & $50.0 \%$ & 3606 & $50.0 \%$ & - & & - & & 526 & $7.3 \%$ & - & - & & 267 & $3.7 \%$ \\
\hline Achemos et al [27] & 292 & $65(+/-14.1)^{\wedge}$ & 199 & $68.2 \%$ & 93 & $31.8 \%$ & 69 & $23.6 \%$ & - & & 69 & $23.6 \%$ & $113.8 \%$ & 11 & $3.8 \%$ & - & \\
\hline Remes-Troche et al [28] & 112 & $43.72(+/-15)^{\wedge}$ & 81 & $72.3 \%$ & 31 & $27.7 \%$ & 23 & $20.5 \%$ & - & & 20 & $17.9 \%$ & $8 \quad 7.1 \%$ & 8 & $7.1 \%$ & 11 & $9.8 \%$ \\
\hline
\end{tabular}




\section{Discussion}

In this study, we found that many of the hospitalized patients with the COVID-19 infection had at least one gastrointestinal symptom. Diarrhea and abdominal pain were the most analyzed symptoms, followed by vomiting, nausea and anorexia, in that order. Most patients with COVID-19 present typical respiratory signs and symptoms. [6] However, it is noticed that gastrointestinal symptoms are a common complaint in patients with COVID-19, [6,25, 26] particularly associated with fever and respiratory symptoms. [6,13]

Digestive symptoms can occur in the absence of respiratory symptoms, but it is rare. [6;7] Some studies have shown that before the onset of respiratory symptoms, the first clinical manifestations in some patients were diarrhea, abdominal pain and nausea. [23]

This Patients with COVID-19 who have digestive symptoms take longer from symptoms to hospital admission than patients without digestive symptoms; this may reflect delayed diagnosis, because typical respiratory symptoms were not initially prevalent. [6] The probability of a positive test for COVID-19 was higher, associated with a 70\% increase in the risk of positive tests, in patients with gastrointestinal symptoms such as diarrhea, nausea or vomiting. [4]

Patients without the classic case of fever associated with respiratory symptoms contribute to the potential risk of infection for front line health professionals and represent a greater challenge for the early diagnosis of patients with COVID-19. [23]

Patients with gastrointestinal symptoms deserve special attention, and it is extremely important to understand the nuances of clinical characteristics and prognosis among patients with and without these symptoms. [23] Our findings could be explained by a prevalent Gastrointestinal viral localization rather than respiratory. The gastrointestinal tropism of SARS-CoV2 has been demonstrated in a recent study that detected SARS-CoV2 more frequently in the stools of patients presenting with diarrhea. [27]

Pan et al [6] and Díaz et al [26] report that there are some reasons why COVID-19 can cause respiratory symptoms. Since SARS-CoV-2 is similar to SARS-CoV and may be able to invade the human body through Angiotensin-Converting Enzyme 2 (ACE-2). Liam et al [18] says: "SARS-CoV-2 is an enveloped virion with approximately $50200 \mathrm{~nm}$ diameter and a single positive sense Ribonucleic acid (RNA) genome. The envelope spike (s) protein is capable of mediating receptor binding and membrane fusion, vital for determining host tropism and transmission capacity. Since intestinal epithelial cells have a high ACE2 level which is the target of SARS-CoV-2, it is plausible that the virus could invade the gastrointestinal tract through this pathway."

Associated with this, it is suggested that the virus can replicate in the intestinal epithelium [26]. SARS-CoV-2 indirectly or directly through a chain reaction of the inflammatory response and viremia can damage the digestive system, initially causing liver tissue damage. Another way is that the Virus itself causes disturbances in the intestinal flora and this alteration of the composition or function changes the intestinal immunological functions. The more severe the stage of the disease, the more gastrointestinal symptoms become more evident, perhaps due to greater viral replication. [6]

\section{Conclusion}

Patients without the classic case of fever associated with respiratory symptoms contribute to the potential risk of infection for front line health professionals and represent a greater challenge for the early diagnosis of patients with COVID-19.[23] Patients with gastrointestinal symptoms deserve special attention, and it is extremely important to understand the nuances of clinical characteristics and prognosis among patients with and without these symptoms. [23].

\section{Compliance with ethical standards}

\section{Acknowledgments}

To all health professionals who are at the front of the battle, taking care, treating and always comforting their Patients.

\section{Disclosure of conflict of interest}


The authors disclose no conflicts.

\section{References}

[1] Wong SH, Lui RN and Sung JJ. (2020).COVID-19 and the digestive system. Journal of Gastroenterology \& Hepatology, 35(5), 744-748.

[2] Jin X, Lian JS, Hu JH, Gao J, Zheng L, Zhang YM, Hao SR, Jia HY, Cai H, Zhang XL, Yu GD, Xu KJ, Wang XY, Gu JQ, Zhang SY, Ye CY, Jin CL, Lu YF, Yu X, Yu XP, Huang JR, Xu KL, Ni Q, Yu CB, Zhu B, Li YT, Liu J, Zhao H, Zhang X, Yu L, Guo YZ, Su JW, Tao JJ, Lang GJ, Wu XX, Wu WR, Qv TT, Xiang DR, Yi P, Shi D, Chen Y, Ren Y, Qiu YQ, Li LJ, Sheng J and Yang Y. (2020). Epidemiological, clinical and virological characteristics of 74 cases of coronavirus-infected disease 2019 (COVID-19) with gastrointestinal symptoms. Gut, 69(6), 1002-1009.

[3] Tian Y, Rong L, Nian W and He Y. (2020). Review article: gastrointestinal features in COVID-19 and the possibility of faecal transmission. Aliment Pharmacol Ther, 51(9), 843-851.

[4] Nobel YR, Phipps M, Zucker J, Lebwohl B, Wang TC, Sobieszczyk ME and Freedberg DE. (2020). Gastrointestinal Symptoms and COVID-19: Case-Control Study from the United States. Gastroenterology, 12(20), 30490-X.

[5] Cheung KS, Hung IF, Chan PP, Lung KC, Tso E, Liu R, Ng YY, Chu MY, Chung TW, Tam AR, Yip CC, Leung KH, YimFong Fung A, Zhang RR, Lin Y, Cheng HM, Zhang AJ, To KK, Chan KH, Yuen KY and Leung WK. (2020). Gastrointestinal Manifestations of SARS-CoV-2 Infection and Virus Load in Fecal Samples from the Hong Kong Cohort and Systematic Review and Meta-analysis. Gastroenterology, 3(20), 30448-0.

[6] Pan L, Mu M, Yang P, Sun Y, Wang R, Yan J, Li P, Hu B, Wang J, Hu C, Jin Y, Niu X, Ping R, Du Y, Li T, Xu G, Hu Q and Tu L. (2020). Clinical Characteristics of COVID-19 Patients With Digestive Symptoms in Hubei, China: A Descriptive, Cross- Sectional, Multicenter Study. The American Journal of Gastroenterology, 115(5), 766-773.

[7] Lin L, Jiang X, Zhang Z, Huang S, Zhang Z, Fang Z, Gu Z, Gao L, Shi H, Mai L, Liu Y, Lin X, Lai R, Yan Z, Li X and Shan H. (2020). Gastrointestinal symptoms of 95 cases with SARS-CoV-2 infection. Gut, 69(6), 997-1001.

[8] Zhu J, Ji P, Pang J, Zhong Z, Li H, He C, Zhang J and Zhao C. (2020). Clinical characteristics of 3062 COVID-19 patients: A meta-analysis. Journal of medical virology, 10(1002), jmv.25884.

[9] Cipriano M, Ruberti E and Giacalone A. (2020). Gastrointestinal Infection Could Be New Focus for Coronavirus Diagnosis. Cureusm 12(3), e7422.

[10] Schmulson M, Dávalos MF and Berumen J. (2020). Beware: Gastrointestinal symptoms can be a manifestation of COVID-19. Rev Gastroenterol Mex, 15 (20)30044-6.

[11] Redd WD, Zhou JC, Hathorn KE, McCarty TR, Bazarbashi AN, Thompson CC, Shen L and Chan WW. (2020). Prevalence and Characteristics of Gastrointestinal Symptoms in Patients with SARS-CoV-2 Infection in the United States: A Multicenter Cohort Study. Gastroenterology, 22(20), 30564-3.

[12] Klopfenstein T, Kadiane-Oussou NJ, Royer PY, Toko L, Gendrin V and Zayet S. (2020). Diarrhea: An underestimated symptom in Coronavirus disease 2019. Clinics and Research in Hepatology and Gastroenterology, 27(20), 30105-4.

[13] Zhang JJ, Dong X, Cao YY, Yuan YD, Yang YB, Yan YQ, Akdis CA and Gao YD. (2020). Clinical characteristics of 140 patients infected with SARS-CoV-2 in Wuhan, China. Allergy, 20, 1-12.

[14] Guan WJ, Ni ZY, Hu Y, Liang WH, Ou CQ, He JX, Liu L, Shan H, Lei CL, Hui DSC, Du B, Li LJ, Zeng G, Yuen KY, Chen RC, Tang CL, Wang T, Chen PY, Xiang J, Li SY, Wang JL, Liang ZJ, Peng YX, Wei L, Liu Y, Hu YH, Peng P, Wang JM, Liu JY, Chen Z, Li G, Zheng ZJ, Qiu SQ, Luo J, Ye CJ, Zhu SY and Zhong NS. (2020). China Medical Treatment Expert Group for COVID-19. Clinical Characteristics of Coronavirus Disease 2019 in China. New England Journal of Medicine, 382(18), 1708-1720.

[15] Chen N, Zhou M, Dong X, Qu J, Gong F, Han Y, Qiu Y, Wang J, Liu Y, Wei Y, Xia J, Yu T, Zhang X and Zhang L. (2020). Epidemiological and clinical characteristics of 99 cases of 2019 novel coronavirus pneumonia in Wuhan, China: a descriptive study. Lancet, 395(10223), 507-513.

[16] Zhou Z, Zhao N, Shu Y, Han S, Chen B and Shu X. (2020). Effect of Gastrointestinal Symptoms in Patients With COVID-19. Gastroenterology, 158(8), 2294-2297.

[17] Zhang G, Hu C, Luo L, Fang F, Chen Y, Li J, Peng Z and Pan H. (2020). Clinical features and short-term outcomes of 221 patients with COVID-19 in Wuhan, China. Journal of Clinical Virology, 127(20), 104364. 
[18] Lian J, Jin X, Hao S, Jia H, Cai H, Zhang X, Hu J, Zheng L, Wang X, Zhang S, Ye C, Jin C, Yu G, Gu J, Lu Y, Yu X, Xiang D, Li L, Liang T, Sheng J and Yang Y. (2020). Epidemiological, clinical, and virological characteristics of 465 hospitalized cases of coronavirus disease 2019 (COVID-19) from Zhejiang province in China. Influenza Other Respiratory Viruses, 12(20), jirv.12758.

[19] Wang X, Fang J, Zhu Y, Chen L, Ding F, Zhou R, Ge L, Wang F, Chen Q, Zhang Y and Zhao Q. (2020). Clinical characteristics of non-critically ill patients with novel coronavirus infection (COVID-19) in a Fangcang Hospital. Clinical Microbiology and Infection, 3(20), 30177-4.

[20] Redd WD, Zhou JC, Hathorn KE, McCarty TR, Bazarbashi AN, Thompson CC, Shen L and Chan WW. (2020). Prevalence and Characteristics of Gastrointestinal Symptoms in Patients with SARS-CoV-2 Infection in the United States: A Multicenter Cohort Study. Gastroenterology, 22(20), 30564-3.

[21] Liu JY, Chen TJ and Hwang SJ. (2020). Analysis of Imported Cases of COVID-19 in Taiwan: A Nationwide Study. International Journal of Environmental Research and Public Health, 17(9), 3311.

[22] Chen Q, Zheng Z, Zhang C, Zhang X, Wu H, Wang J, Wang S and Zheng C. (2020). Clinical characteristics of 145 patients with corona virus disease 2019 (COVID-19) in Taizhou, Zhejiang, China. Infection, 28(20), 1-9.

[23] Zheng T, Yang C, Wang HY, Chen X, Yu L, Wu ZL and Sun H. (2020).Clinical characteristics and outcomes of COVID19 patients with gastrointestinal symptoms admitted to Jianghan Fangcang Shelter Hospital in Wuhan, China. Journal of medical Virology, 10(20), jmv.26146.

[24] Shang Y, Xu C, Jiang F, Huang R, Li Y, Zhou Y, Xu F and Dai H. (2020).Clinical characteristics and changes of chest CT features in 307 patients with common COVID-19 pneumonia infected SARS-CoV-2: A multicenter study in Jiangsu, China. International Journal of Infectious Disesases, 8(96), 157-162.

[25] Chen A, Agarwal A, Ravindran N, To C, Zhang T and Thuluvath PJ. (2020).Are Gastrointestinal Symptoms Specific for COVID-19 Infection? A Prospective Case- Control Study from the United States. Gastroenterology, 15 (20), 30664-8.

[26] Díaz LA, García-Salum T, Fuentes-López E, Ferrés M, Medina RA, Riquelme A; Contributors, Levican J, Almonacid LI, Serrano E, Chahuan J, Cofré C, Álvarez M, Labarca J, Valderrama S, Salinas E, Toro A, Ortega M, García P and Pizarro M. (2020).Symptom profiles and risk factors for hospitalization in patients with SARS-CoV-2 and COVID19: A Large Cohort from South America. Gastroenterology, 8(20), 30606-5.

[27] Aghemo A, Piovani D, Parigi TL, Brunetta E, Pugliese N, Vespa E, Omodei PD, Preatoni P, Lleo A, Repici A, Voza A, Cecconi M, Malesci A, Bonovas S and Danese S (2020).Humanitas COVID-19 Task Force. COVID-19 digestive system involvement and clinical outcomes in a large academic hospital in Milan, Italy. Clinical Gastroenterology Hepatology, 10(20), 30646-7.

[28] Remes-Troche JM, Ramos-de-la-Medina A, Manríquez-Reyes M, Martínez-Pérez- Maldonado L, Lara EL and SolísGonzález MA. Initial Gastrointestinal Manifestations in Patients with SARS-CoV-2 in 112 patients from Veracruz (Southeastern Mexico). Gastroenterology, 21(20), 34708-9.

\section{How to cite this article}

Rocha GH, Campos MV and Melo BV. (2020). Gastrointestinal manifestations in patients with COVID-19 infection. World Journal of Advanced Research and Reviews, 7(1), 73-78. 